\title{
Overweight, obesity and female sexuality in perimenopause: a preliminary report
}

\author{
Grażyna Jarząbek-Bielecka ${ }^{1}$, Maciej Wilczak ${ }^{2,3}$, Anna Potasińska-Sobkowska \\ Magdalena Pisarska-Krawczyk ${ }^{2,3}$, Małgorzata Mizgier ${ }^{5}$, Karolina Andrzejak ${ }^{6}$, Witold Kędzia ${ }^{1}$, Stefan Sajdak ${ }^{6}$ \\ ${ }^{1}$ Chair of Adolescence Gynaecology and Sexuology, Clinic of Gynaecology, Faculty of Perinatology and Gynaecology, Poznan University \\ of Medical Sciences, Poznan, Poland \\ 2Department of of Mother's and Child's Health, Poznan University of Medical Sciences, Poznan, Poland \\ ${ }^{3}$ Higher Vocational State School of President Stanisław Wojciechowski in Kalisz, Kalisz, Poland \\ ${ }^{4}$ Chair and Department of Medical Education, Poznan University of Medical Sciences, Poznan, Poland \\ ${ }^{5}$ Department of Hygiene and Human Nutrition, Dietetic Division, Poznan University of Life Science, Poland \\ ${ }^{6}$ Department of Surgical Gynaecology, Poznan University of Medical Sciences, Poznan, Poland
}

\begin{abstract}
Introduction: The research was conducted among patients of the Department of Perinatology and Gynaecology of the Poznań University of Medical Sciences. Its aim was to investigate the influence of overweight and obesity on female sexuality during the perimenopausal period. Preliminary results of the research are presented in the thesis, which was as a matter of fact intended as a preliminary report. The examination of sexual functions of the patients was performed with the use of the Female Sexual Function Index (FSFI) form.

Material and methods: Sixty-one women during the perimenopausal period filled out the survey, with the average age of these women being 51 years. Forty-two of the examined women had an appropriate body mass index (BMI), i.e. between 18.5 and 25, while for 19 of the women, the BMI was above normal. For statistical analysis and in order to assess the differences between the two above-mentioned groups of patients, the nonparametric Mann-Whitney test was applied. A statistically significant value was assumed at $p<0.05$. The results of the conducted research indicated no such difference between the women with differing BMI for the specific domains of the FSFI test.

Results: The results obtained show that research in the area needs to be continued.

Conclusions: All the hitherto existing scientific studies also seem to indicate that the influence of overweight and obesity on female sexuality during the perimenopause has not yet been unambiguously proven. Beyond any doubt, however, sexual disorders appear in women at this time of life and the factors which determine them can vary greatly. Given the character of the situation, women ought to be supported both by a team of specialists representing different branches of medicine as well as by their relatives. The whole situation also calls for more research of the important subject matter.
\end{abstract}

Key words: female sexuality, overweight, obesity, perimenopause.

\section{Introduction}

There are few reports relating overweight and obesity to female sexuality in perimenopause. For this reason, the present thesis attempts to research the issue and its aim is to assess the subject matter in some detail.

Data on sexual functions of female patients were collected through the Female Sexual Function Index (FSFI) form.

No statistically significant difference in terms of the FSFI form was found between women with correct body weight and overweight or obese women. However, as follows from the literature of the subject, sexual disorders are related to both overweight and obesity and to diseases that follow from obesity, i.e. diabetes, car- diovascular disease (CVD) and mental disorders [1-4]. Therefore - in order to prevent or treat these disorders - care of women in perimenopause ideally ought to assume some form of co-operation between a gynaecologist, a dietician and a psychiatrist. This can include hormone replacement therapy (HRT), correct diet therapy paired with correct physical activity, often also combined with antidepressants (usually of the selective serotonin reuptake inhibitors [SSRI] type). Co-operation between specialists is important not only at the stage of implementing the treatment - it has a significant role also in relation to the necessity of monitoring the results of the therapy as well as the potential intensification of undesirable results stemming from the use of hormonal and psychotropic pharmaceuticals. 


\section{Material and methods}

The study was conducted among a group of 61 women during the perimenopausal period. Forty-two of the women had an appropriate body mass index (BMI) while for 19 of them the BMI was above normal. The average age of women was 51 years. To conduct the research, the FSFI form was used and then statistical analysis was applied. The present thesis is a preliminary report and the research is continuing at the Department of Perinatology and Gynaecology of the Poznań University of Medical Sciences.

\section{Results}

The relations between the Female Sexual Function Index and body mass index among women

Due to the nature of the data (unrepresentative spread), in order to assess the differences between

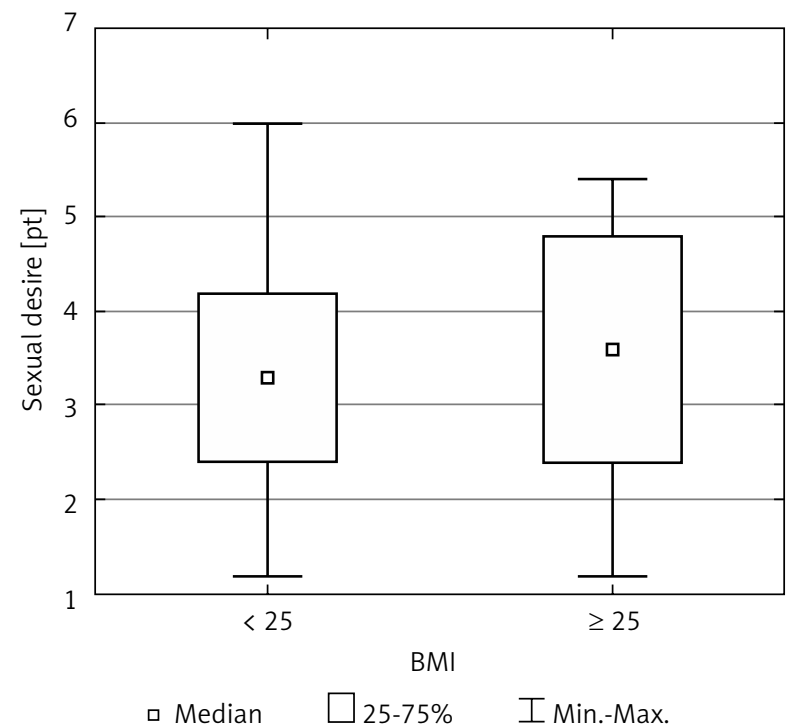

Fig. 1. The relation between domain of sexual desire and BMI among women the average values of two independent samples, the nonparametric Mann-Whitney test was applied. A statistically significant value was assumed at $p<0.05$.

\section{The relation between the domain of sexual desire and body mass index among women}

No statistically significant difference was observed between women with different values of BMI for the domain of sexual desire (Table I) (Fig. 1).

\section{The relation between the domain of sexual arousal and body mass index among women}

No statistically significant difference was observed between women with different values of BMI for the domain of sexual arousal (Table II) (Fig. 2).

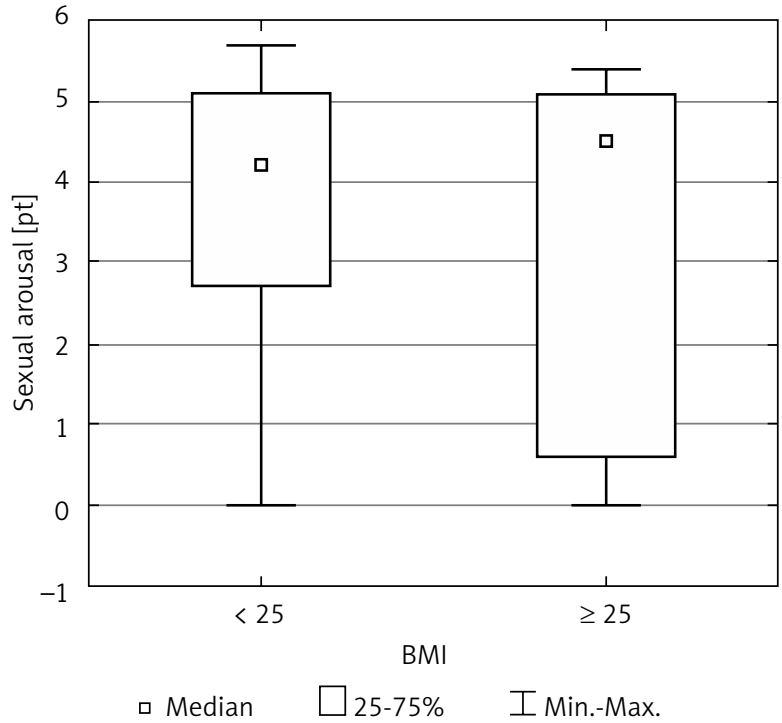

Fig. 2. The relation between domain of sexual arousal and BMI among women

Tab. I. Descriptive statistics and the results of the Mann-Whitney test for the domain of sexual desire

\begin{tabular}{|c|c|c|c|c|c|c|c|c|}
\hline BMI & $n$ & Average & SD & Median & Min. & Max. & $U^{*}$ & $p$ \\
\hline$<25$ & 42 & 3.36 & 1.31 & 3.30 & 1.2 & 6.0 & \multirow{2}{*}{398.0} & \multirow{2}{*}{0.993787} \\
\hline$\geq 25$ & 19 & 3.28 & 1.36 & 3.60 & 1.2 & 5.4 & & \\
\hline
\end{tabular}

${ }^{*} U$ - value of the Mann-Whitney test

$\mathrm{BMI}$ - body mass index

Tab. II. Descriptive statistics and the results of the Mann-Whitney test for the domain of sexual arousal

\begin{tabular}{ccccccccc}
\hline BMI & $\boldsymbol{N}$ & Average & SD & Median & Min. & Max. & $U^{*}$ & $p$ \\
\hline$<25$ & 42 & 3.75 & 1.77 & 4.20 & 0.0 & 5.7 & & 382.5 \\
\hline$\geq 25$ & 19 & 3.43 & 2.09 & 4.50 & 0.0 & 5.4 & & 0.803222 \\
\hline
\end{tabular}

${ }^{*} U$ - value of the Mann-Whitney tes

$\mathrm{BMI}$ - body mass index 


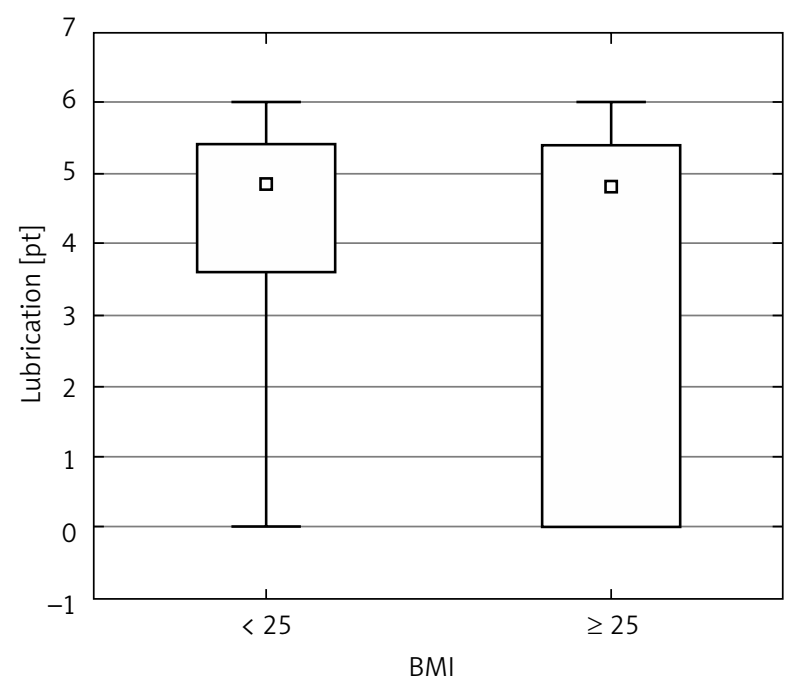

- Median $\square 25-75 \%$ I Min.-Max.

Fig. 3. The relation between lubrication domain and BMI among women

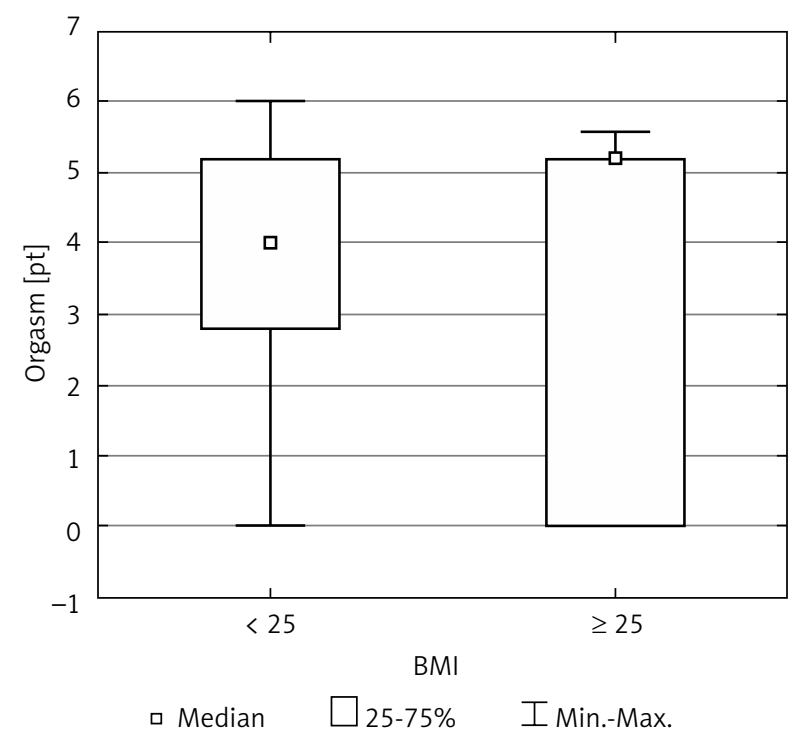

Fig. 4. The relation between orgasm domain and BMI among women

Tab. III. Descriptive statistics and the results of the Mann-Whitney test for the lubrication domain

\begin{tabular}{lcccccccc}
\hline BMI & $\boldsymbol{N}$ & Average & SD & Median & Min. & Max. & $\boldsymbol{U}^{*}$ & $\boldsymbol{P}$ \\
\hline$<25$ & 42 & 4.12 & 1.94 & 4.80 & 0.0 & 6.0 & 357.5 \\
\hline$\geq 25$ & 19 & 3.65 & 2.35 & 4.80 & 0.0 & 6.0 & \\
\hline${ }^{*} U$ - value of the Mann-Whitney test & & & & &
\end{tabular}

$\mathrm{BMI}$ - body mass index

Tab. IV. Descriptive statistics and the results of the Mann-Whitney test for the orgasm domain

\begin{tabular}{ccccccccc}
\hline BMI & $n$ & Average & SD & Median & Min. & Max. & $U^{*}$ & $p$ \\
\hline$<25$ & 42 & 3.67 & 1.93 & 4.00 & 0.0 & 6.0 & & 353.0 \\
\hline$\geq 25$ & 19 & 3.77 & 2.35 & 5.20 & 0.0 & 5.6 & & 0.478570 \\
\hline
\end{tabular}

${ }^{*} U$ - value of the Mann-Whitney test

$\mathrm{BMI}$ - body mass index

\section{The relation between the lubrication domain and body mass index among women}

No statistically significant difference was observed between women with different values of BMI for the lubrication domain (Table III) (Fig. 3).

\section{The relation between the orgasm domain and body mass index among women}

No statistically significant difference was observed between women with different values of BMI for the orgasm domain (Table IV) (Fig. 4).

\section{The relation between the domain of sexual satisfaction and body mass index among women}

No statistically significant difference was observed between women with different values of BMI for the domain of sexual satisfaction (Table V) (Fig. 5).
The relation between the domain of sexual pain and body mass index among women

No statistically significant difference was observed between women with different values of BMI for the domain of sexual pain (Table VI) (Fig. 6).

The relation between the fotal Female Sexual Function Index and body mass index among women

No statistically significant difference was observed between women with different values of BMI for total FSFI (Table VII) (Fig. 7).

\section{Discussion}

Human sexuality is an important element of the development of the personality. As a rule, it is a positive driving force in the human population, motivating 


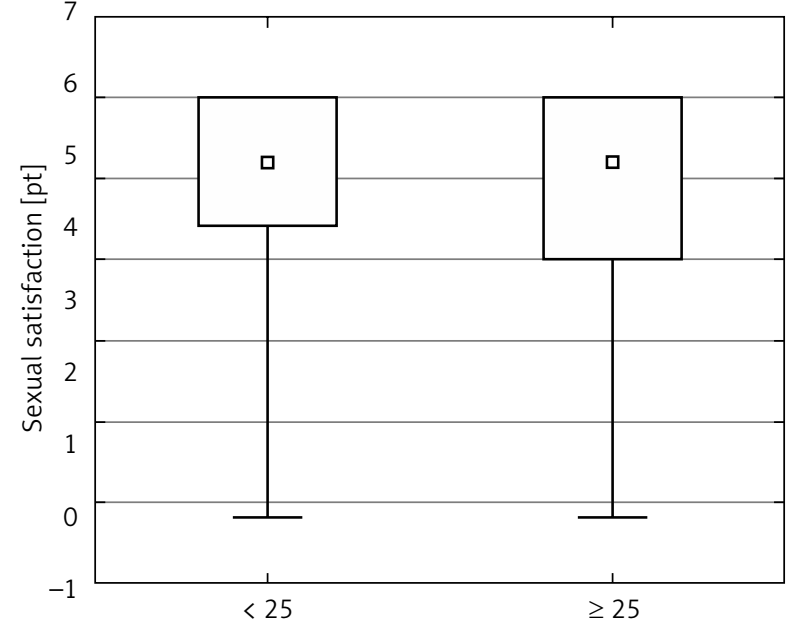

$\mathrm{BMI}$

$\square$ Median

$\square 25-75 \%$

IMin.-Max

Fig. 5. The relation between domain of sexual satisfaction and BMI among women

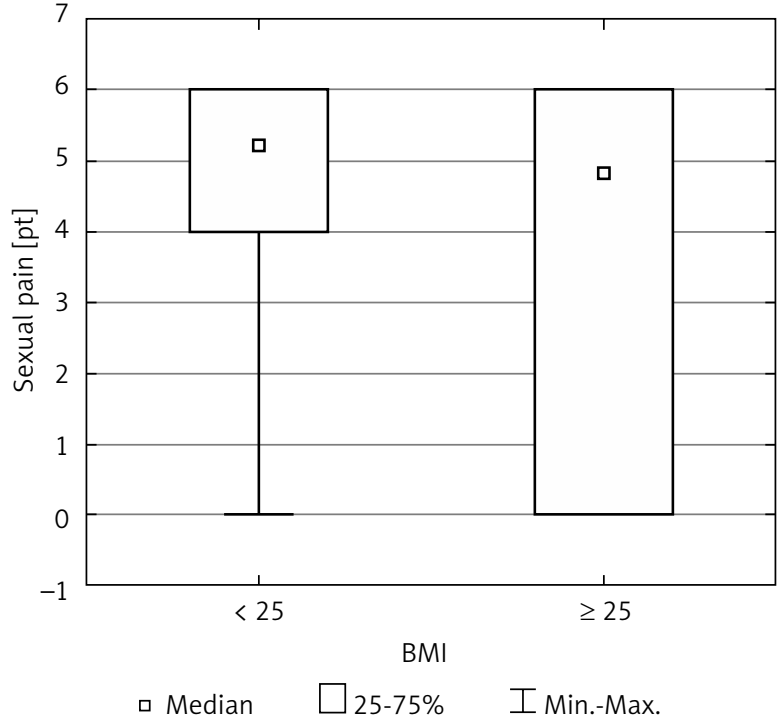

Fig. 6. The relation between domain of sexual pain and BMI among women

Tab. V. Descriptive statistics and the results of the Mann-Whitney test for the domain of sexual satisfaction

\begin{tabular}{|c|c|c|c|c|c|c|c|c|}
\hline BMI & $N$ & Average & SD & Median & Min. & Max. & $U^{*}$ & $p$ \\
\hline$<25$ & 42 & 4.62 & 1.66 & 5.20 & 0.8 & 6.0 & \multirow{2}{*}{381.5} & \multirow{2}{*}{0.791199} \\
\hline$\geq 25$ & 19 & 4.61 & 1.77 & 5.20 & 0.8 & 6.0 & & \\
\hline
\end{tabular}

${ }^{*} U$ - value of the Mann-Whitney test

$\mathrm{BMI}$ - body mass index

Tab. VI. Descriptive statistics and the results of the Mann-Whitney test for the domain of sexual pain

\begin{tabular}{ccccccccc}
\hline BMI & $\boldsymbol{N}$ & Average & SD & Median & Min. & Max. & $U^{*}$ & $p$ \\
\hline$<25$ & 42 & 4.46 & 2.03 & 5.20 & 0.0 & 6.0 & & 0.478570 \\
\hline$\geq 25$ & 19 & 3.85 & 2.47 & 4.80 & 0.0 & 6.0 & & 353.0 \\
\hline
\end{tabular}

* $U$ - value of the Mann-Whitney test

$\mathrm{BMI}$ - body mass index

Tab. VII. Descriptive statistics and the results of the Mann-Whitney test for total Female Sexual Function Index (FSFI)

\begin{tabular}{|c|c|c|c|c|c|c|c|c|}
\hline BMI & $N$ & Average & SD & Median & Min. & Max. & $U^{*}$ & $p$ \\
\hline$<25$ & 42 & 23.97 & 9.49 & 26.20 & 2.0 & 34.3 & \multirow{2}{*}{397.5} & \multirow{2}{*}{0.987574} \\
\hline$\geq 25$ & 19 & 22.59 & 11.61 & 28.20 & 3.2 & 33.2 & & \\
\hline
\end{tabular}

${ }^{*} U$ - value of the Mann-Whitney test

$\mathrm{BMI}$ - body mass index

individuals to engage in interaction and to form interpersonal relationships $[5,6]$.

Although the results of the conducted research seem to point out to no statistically significant difference between women with varying BMI and FSFI results in general, this very outcome of the research proves the necessity of continuing the research of this significant subject matter. The perimenopausal period, also known as menopause or climacteric, is a natural biological process which results in women at about 45-50 years of age in decreasing their production of oestrogens until the point where it finally stops. It is initially signalled by irregular menstrual cycles and then their final termination, i.e. menopause [6-8].

Women during the period suffer from hot flushes and hyperhidrosis (more commonly known as the night sweats), constant fatigue and apathy, dejection, loss of libido, irritability, nervousness, problems with concentration and memory, sleep disorders, vaginal dryness, problems with sexual intercourse, and stress urinary incontinence. The intensity and duration of these ailments vary among women and they might appear as soon as 
5 years before menopause and last for up to 5 years after the termination of menstrual cycles $[6,9,10]$.

Many women in this period suffer from depression - clinical research as well as many other forms of research all prove that the disorder appears more in women in perimenopause than in women before or after the period. The researched group was not diagnosed with depression - a fact which could have positive repercussions on sexual activity of the women and thus might have led to the conclusions obtained. One must bear in mind that one of the sources of oestradiol is the adipose tissue. The functioning of the human body is conditioned by each hormone and the mutual relation between hormones, which in turn is controlled through the process of conversion [6, 10].

Nowadays it is believed that the appearance and/or intensification of the symptoms of depression in perimenopause as well as the consequent sexual disorders are related not only to the fluctuation of concentrations of oestrogens. Perhaps the conversion of oestrogens in the adipose tissue for the examined obese women compensated for their potential loss in the acceptance of their own physical appearance. Life changes in their family, their profession or within the circle of their acquaintances along with the changing sense of their own body and femininity - most visibly pronounced in obese women - usually also affect the sphere of sexuality $[1,3,4,6,10]$.

The risk of depression and of consequent sexual disorders in perimenopause is greater also due to the intensified negative perception of the changes in lifestyle, mostly in the areas of maternity, family life, professional life, fertility, fitness and physical attractiveness (related to the increase in body weight) $[1,5,7,8]$.

At this point it is therefore worth mentioning that the co-operation between a gynaecologist, a dietician and a psychiatrist in treating an obese female patient in the perimenopausal period is crucial. Diagnosing perimenopausal depression mainly follows from careful medical research about the current mental state of the patient as well as from taking into account the patient's previous episodes of mood problems and any other mental crises. As mentioned above, the examined women had not suffered from depression, which might have influenced the lack of statistically significant differences in terms of the FSFI form in the two examined groups. Satisfactory sex life prevents depression - including perimenopausal depression [7, 9, 11].

It has been known for years that satisfactory sex life has a significant influence on the length and quality of life. It exerts a protective influence with regard to various diseases including myocardial infarctions, strokes, migraines and the above-mentioned depression. Sexual disorders can have biological, psychological and social background in both men and women. Sexual dysfunctions are becoming increasingly common due to the

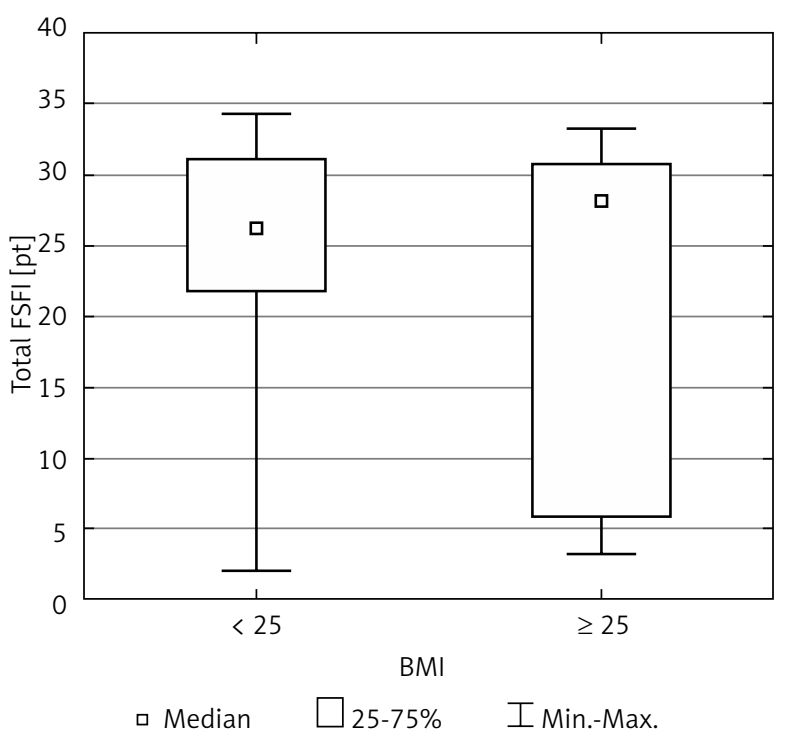

Fig. 7. The relation between total Female Sexual Function Index (FSFI) and BMI among women

increasing pace of life and high levels of stress, as well as the decrease in overall public health and a steady increase in civilisation diseases [6].

The results of the very few studies of the relation between obesity and sexual disorders in women have been inconclusive $[12,13]$, therefore, in spite of the fact that the conducted research shows no statistically significant difference between women with the varying $\mathrm{BMI}$ and FSFI forms, there is a necessity of continued research of this important issue. It is even truer with regard to the fact that overweight and obesity have also been classified as a risk factor for sexual disorders in men [2, 13].

It must not be overlooked that along with the increase in the percentage of people suffering from sexual disorders $[14,15]$ there has been an increase in the occurrence of risk factors for these disorders, such as overweight and obesity, carbohydrate balance disorders and lipid disorders [1, 16-20]. Treating illnesses related to the occurrence of sexual disorders or modifying those risk factors which follow from a person's lifestyle (by including into the programme an individual diet therapy and appropriate physical activity) can successfully prevent the occurrence of the disorders or at least prevent their intensification. This is particularly significant for women in perimenopause as dysfunctions in female sexuality increase with age (as does erectile dysfunction in men) [21-23].

Obesity - a result of poor nutrition and a lack of physical activity - has a distinctly negative impact on the sexual health of both sexes. It is a very frequent cause of sexual disorders and it can even prevent sexual contact in the case of extreme abdominal girth of one of or both partners. Moreover, it has a negative impact on the feeling of femininity, masculinity and 
the general mental state, all of which often makes sexual initiation impossible. The incidence of sexual dysfunction is observed slightly more frequently in women (at 25-63\%) than in men (where it amounts to $10-52 \%)$ [24].

Obese people are socially less accepted than their more slim peers, a fact which naturally decreases their social self-esteem $[1,3,4,25]$. In comparison to the normal body weight population, obese people are burdened with an irregular rhythm of insulin secretion, which increases their risk of developing diabetes [26].

Secondary changes in blood vessels and within the peripheral nervous system contribute to sexual dysfunctions, mainly the loss of libido in both sexes. If the changes in blood vessels spread all over the body, they lead to the impairment of the endothelium and to peripheral neuropathy [27].

Male diabetics run three times as high a risk of erection problems compared with the healthy part of the population [28].

A number of theses have been devoted to the biochemical pathogenesis of testosterone deficiency in diabetics. The consensus is that it is most probably related to the decrease in serotonin secretion as well as to inflammatory cytokines [26].

Obese men suffering from the metabolic syndrome or from type 2 diabetes have low free and bound testosterone as well as low levels of sex hormone binding globulin (SHBG). Obesity - or the excess of the adipose tissue, to be precise - influences the suppression of SHBG and indirectly the total concentration of testosterone in blood [26].

Visceral fat is an active secretory tissue which produces inflammatory cytokines and biochemical modulators, which in turn may cause vascular inflammation and also trigger endothelial dysfunction [26].

Sexual disorders are common among the population of patients suffering from arterial hypertension [28].

Abnormalities of the system responsible for vasoconstriction, i.e. the narrowing of blood vessels, play an important role in the pathogenesis of erectile dysfunction. Therefore, if a patient is diagnosed with arteriosclerosis, he will be predicted to later develop erectile dysfunction. Similarly, patients suffering from erectile dysfunction are likely to suffer from cardiovascular and peripheral vascular diseases later on in their lives [28].

Pharmaceuticals used in the treatment of arterial hypertension may also cause or exacerbate sexual dysfunctions, leading to patient dissatisfaction with pharmacotherapy [24].

Erection is extremely unfavourably affected by preparations of the beta-adrenolytic type due to the hindering effect they exert on the sympathetic nervous system. These preparations can block the cavernous bodies of the penis and they additionally have both calming and depressing effect [24].
Obese patients suffering from arterial hypertension should not be treated with the use of the diuretics or $\beta$-adrenolytics as these medications may increase the incidence of metabolic disorders and consequently exacerbate erectile dysfunction. Angiotensin-convertingenzyme (ACE) inhibitors, i.e. angiotensin-converting enzyme inhibitors and calcium channel blockers are the preferred form of therapy as they demonstrate neutral effects on sexual performance [24].

Care of women in perimenopause ideally ought to assume some form of co-operation between a gynaecologist, a dietician and a psychiatrist. This can include hormone replacement therapy (HRT) - typically comprising preparations containing oestrogens and administered orally, vaginally, percutaneously or intramuscularly, correct diet therapy paired with correct physical activity, often also combined with antidepressants (usually of the selective serotonin reuptake inhibitors [SSRI] type). Co-operation between specialists is important not only at the stage of implementing the treatment, it has a significant role also in relation to the necessity of monitoring the results of the therapy as well as the potential intensification of undesirable results stemming from the use of hormonal and psychotropic pharmaceuticals [29].

Recommending hormone replacement therapy (based on oestrogen) to women with symptoms of the perimenopausal period is justified as long as the decision to implement the therapy is made with the approval of the patient's general doctor and after taking into account the risk factors (cardiovascular disease and breast cancer) as well as potential benefits stemming from the treatment [30].

Hormone replacement therapy can decrease the strength of hot flushes and beneficially influence the patient's functioning in the sexual sphere as well as her quality of sleep, and for some women it can also alleviate the symptoms of depression. Although the treatment is not strictly antidepressant in nature, by increasing the activity of neurotransmitters it can positively affect the patient's mood, reduce the intensity of the somatic symptoms of menopause, improve the ability to concentrate as well as improve memory and the quality of sleep. For some women it might be advisable to combine the hormone therapy with an antidepressant medication. Clinical observations suggest that administering oestrogens generally and/or vaginally improves the quality of the patient's sex life $[6,10]$.

Experts also recommend a change in lifestyle: physical activity and correct nutritional habits. It might also be advisable for some patients to use supportive psychotherapy or cognitive behavioural therapy [5, 7, 23].

As mentioned earlier, changes in lifestyle might have a positive influence both directly on sexual functions as well as on the therapy and prevention of over- 
weight and obesity, diabetes, arterial hypertension and lipid disorders [2, 22].

The research conducted by Aversa - where the sexuality of obese women aged 18-49 years was examined through the prism of the FSFI- 6 form - led to the conclusion that as soon as after 16 weeks of a well-balanced diet and correct physical activity there was a significant improvement for the examined women in their moisturising, excitement as well as satisfaction coming from a sexual intercourse. The changes to the women's lifestyle also affected the loss of body weight, improved the functioning of endothelium and decreased their in sulin resistance [31].

In another research with a group of women, Hamilton showed that increased physical activity regulated the women's body weight - a thing of great importance for the mental state of the patients (improved self-esteem), which resulted in a consequent increase of sexual excitement [32]. In her studies, Dąbrowska proved that there are fewer sexual disorders - assessed in accordance with the FSFI form - in women with a higher level of physical activity [33].

Studying the influence of the Mediterranean diet on sexual fitness (assessed with the FSFI form for women aged 35-70 years and suffering from type 2 diabetes), Gugliano discovered that there was a lower level of sexual disorders for the patients who obeyed the Mediterranean diet more diligently [34].

At the same time, as numerous studies show - the Mediterranean diet can have a beneficial influence both on the prevention and treatment of obesity, cardiovascular diseases, diabetes, arterial hypertension [35-37].

Very good results in decreasing body weight, lowering the concentration of low-density lipoprotein (LDL)-cholesterol as well as in reducing hypertension can be achieved with the implementation of a low-fat diet ( $\leq 10 \%$ of the daily ration of food) - a diet which is based on unprocessed plant products and which at the same time eliminates animal products [38, 39].

Therefore, it seems most reasonable to include the above dietetic models both as a way to supplement treating sexual disorders and as a part of a prevention programme for women entering the perimenopausal age.

\section{Conclusions}

Optimal care of women during the perimenopausal period should include co-operation between a gynaecologist, a psychiatrist, a dietician and a general doctor as sexual disorders in women in the perimenopause can be determined by a number of factors (among others by overweight, obesity or by diseases appearing in its consequence as well as by mental factors such as depression).

The researched group was not diagnosed with any symptoms of depression - a fact which could have posi- tive repercussions on sexual activity of the women and thus might have led to the conclusions obtained.

The results of the research of the influence of overweight and obesity on female sexuality during the perimenopausal period indicated no statistically significant difference between women with correct body weight and overweight or obese women. The research needs to be continued at the Department of Perinatology and Gynaecology of the Poznań University of Medical Sciences.

\section{Disclosure}

Authors report no conflict of interest.

\section{References}

1. Chedraui P, Pérez-López FR, Blümel JE, et al. Hyperglycemia in postmenopausal women screened for the metabolic syndrome is associated to increased sexual complaints. Gynecol Endocrinol 2010; 26: 86-92.

2. Erenel AŞ, Kılınc FN. Does obesity increase sexual dysfunction in women? Sexuality and Disability 2013; 31: 53-62.

3. Kinzl JF, Trefalt E, Fiala M, et al. Partnership, sexuality, and sexual disorders in morbidly obese women: consequences of weight loss after gastric banding. Obes Surg 2001; 11: 455-458.

4. Morotti E, Battaglia B, Paradisi R, et al. Body mass index, Stunkard Figure Rating Scale, and sexuality in young Italian women: a pilot study. J Sex Med 2013; 10: 1034-1043.

5. Burt VK, Stein K. Epidemiology of depression throughout the female life cycle. J Clin Psychiatry 2002; 63 (Suppl 7): 9-15.

6. Jarząbek-Bielecka G, Sowińska-Przepiera E, Pawlaczyk M. Aging and sexual activity: gynecological, sexological and psychological aspects. Prz Menopauzalny 2012; 11: 487-489.

7. Freeman EW, Sammel MD, Lin H, et al. Associations of hormones and menopausal status with depressed mood in women with no history of depression. Arch Gen Psychiatry 2006; 63: 375-382.

8. Parry BL. Perimenopausal depression. Am J Psychiatry 2008; 165: 23-27.

9. Rajewska J, Rybakowski JK. Depression in premenstrual women: gonadal hormones and serotonergic system assessed by D-fenfluramine challenge test. Prog Neuropsychopharmacol Biol Psychiatry 2003; 27: 705-709.

10. Rasgon NL, Altshuler LL, Fairbanks LA, et al. Estrogen replacement theraphy in the treatment of major depressive disorder in perimenopausal women. J Clin Psychiatry 2002; 63 (Suppl 7): 45-48.

11. Sloan DM, Kornstein SG. Gender differences in depression and response to antidepressant treatment. Psychiatr Clin North Am 2003; 26: 581-594.

12. Esposito K, Ciotola M, Giugliano F, et al. Association of body weight with sexual function in women. Int J Impot Res 2007; 19: 353-357.

13. Yaylali GF, Tekekoglu S, Akin F. Sexual dysfunction in obese and overweight women. Int J Impot Res 2010; 22: 220-226.

14. Ayta IA, McKinlay JB, Krane RJ. The likely worldwide increase in erectile dysfunction between 1995 and 2025 and some possible policy consequences. BJU Int 1999; 84: 50-56.

15. McKinlay JB. The worldwide prevalence and epidemiology of erectile dysfunction. Int J Impot Res 2000; 12 (Suppl 4): 6-11.

16. Esposito K, Ciotola M, Marfella R, et al. Sexual dysfunction in women with the metabolic syndrome. Diabetes Care 2005; 28: 756.

17. Esposito K, Ciotola M, Maiorino MI, et al. Hyperlipidemia and Sexual Function in Premenopausal Women. J Sex Med 2009; 6: 1696-1703.

18. Miner M, Esposito K, Guay A, et al. Cardiometabolic Risk and Female Sexual Health: The Princeton III Summary (CME). J Sex Med 2012; 9: 641-651.

19. Mizgier M, Jarząbek-Bielecka G. Diabetes and sexual dysfunctions during menopause and andropause. Archives of Perinatal Medicine 2014; 20: 35-39.

20. Watts RJ. Sexual function of diabetic and nondiabetic African American women: a pilot study. J Natl Black Nurses Assoc 1994; 7: 50-59. 
21. Camacho ME, Reyes-Ortiz CA. Sexual dysfunction in the elderly: age or disease? Int J Impot Res 2006; 17 (Suppl 1): 52-56.

22. Martelli V, Valisella S, Moscatiello S, et al. Prevalence of sexual dysfunction among postmenopausal women with and without metabolic syndrome. J Sex Med 2012; 9: 434-441.

23. Shah MB. Obesity and sexuality in women. Obstet Gynecol Clin North Am 2009; 36: 347-360.

24. Depko A. Otyłość, nadciśnienie tętnicze a dysfunkcje seksualne. Nadciśnienie Tętnicze 2009; 13: 139-146.

25. Erbil N. The Relationships Between Sexual Function, Body Image, and Body Mass Index Among Women. Sexuality and Disability 2013; 31: 63-70.

26. Wang C, Jackson G, Jones TH, et al. Low testosterone associated with obesity and the metabolic syndrome contributes to sexual dysfunction and cardiovascular disease risk in men with 2 diabetes. Diabetes Care 2011; 34: 1669-1675.

27. Seifert M, Zdrojewicz Z. Otyłość a zachowania seksulane. Endokrynologia, Otyłość i Zaburzenia Przemiany Materii 2010; 6: 129-146.

28. Esposito K, Giugliano D. Obesity, the metabolic syndrome, and sexual dysfunction. Int J Impot Res 2005; 17: 391-398.

29. Bajos N, Wellings K, Laborde C, Moreau C, CSF Group. Sexuality and obesity, a gender perspective: result from French national random probability survey of sexual behaviours. BMJ 2010; 340: 2573.

30. Genazzani AR, Stomati M, Valentino V, et al. Effect of 1-year, low-dose DHEA therapy on climacteric symptoms and female sexuality. Climacteric 2011; 14: 661-668.
31. Aversa A, Bruzziches R, Francomano D, et al. Weight loss by multidisciplinary intervention improves endothelial and sexual function in obese fertile women. J Sex Med 2013; 10: 1024-1033.

32. Hamilton LD, Fogle EA, Meston CM. The roles of testosterone and alphaamylase in exercise-induced sexual arousal in women. J Sex Med 2008; 5: 845-853.

33. Dąbrowska J, Drosdzol A, Skrzypulec V, Plinta R. Physical activity and sexuality in perimenopausal women. Eur J Contracept Reprod Health Care 2010; 15: 423-432.

34. Gugliano F, Maiorino M, Di Palo C, et al. Adherence to Mediterranean diet and sexual function in women with type 2 diabetes. J Sex Med 2010; 7: 1883-1890.

35. Mizgier M, Jeszka J, Jarząbek-Bielecka G. Rola diety śródziemnomorskiej w zapobieganiu nadwadze i otyłości, niektórym chorobom dietozależnym oraz jej wpływ na długość życia. Nowiny Lekarskie 2010; 79 : 451-454.

36. Schroder H, Marrugat J, Vila J, et al. Adherence to the traditional Mediterranean diet is inversely associated with body mass index and obesity in a Spanish population. J Nutr 2004; 134: 3355-3361.

37. Sofi F, Cesari F, Abbate R, et al. Adherence to Mediterranean diet and health status: meta-analysis. Br Med J 2008; 337: 1344.

38. McDougall J, Thomas LE, McDougall C, et al. Effects of 7 days on an ad libitum low-fat vegan diet: the Mc Dougall Program cohort. Nutr J 2014; 13: 99.

39. Ornish D, Scherwitz LW, Billings JH, et al. Intensive Lifestyle Changes for Reversal of Coronary Heart Disease. JAMA 1998; 280: 2001-2007. 